\title{
Revascularization method for patients with infrainguinal arterial disease
}

\section{Glushkov Nikolay, Ivanov Michael, Artemova Anastasia, Puzdriak Petr, Uryupina Anastasia, Bondarenko Pavel, Ivan Tigrov}

Department of General Surgery, North-West State Medical University, Saint Petersburg 195067, Russia.

Correspondence to: Dr. Puzdriak Petr, Department of General Surgery, North-West State Medical University, Saint Petersburg 195067, Russia. E-mail: hirurg495@yandex.ru

How to cite this article: Nikolay G, Michael I, Anastasia A, Petr P, Anastasia U, Pavel B, Tigrov I. Revascularization method for patients with infrainguinal arterial disease. Vesse/ P/us 2018;2:35. http://dx.doi.org/10.20517/2574-1209.2018.45

Received: 9 Jun 2018 First Decision: 28 Aug 2018 Revised: 13 Sep 2018 Accepted: 18 Sep 2018 Published: 29 Oct 2018

Science Editors: Mario F. L. Gaudino, Igor A. Sobenin Copy Editor: Cui Yu Production Editor: Zhong-Yu Guo

\begin{abstract}
Aim: The aim of the study was to perform a comparative evaluation of the use of various methods of reconstructive assistance in the repair of the femoral-tibial segment in patients with peripheral arterial disease.
\end{abstract}

Methods: Two hundred and fifty-three patients with atherosclerotic lesions of arteries below the inguinal ligament were examined and revascularized. According to the type of reconstruction performed, the patients were divided into 3 groups: 98 patients underwent open operative interventions; 116 patients underwent endovascular interventions; 39 had hybrid reconstructions performed.

Results: Minor blood loss, and stability of hemodynamics in the perioperative context positively characterize hybrid effects. The time spent in the resuscitation department and the shorter hospitalization of patients after hybrid revascularization methods were revealed in comparison with open methods. The absence of dangerous complications and the primary patency of the operated segment in the early postoperative period, approaching $100 \%$, characterize hybrid techniques as an effective method of treating patients with infrainguinal arterial disease.

Conclusion: Hybrid technologies are characterized by a shorter duration of surgical intervention, a low amount of blood loss and a lower incidence of complications in the early periods. The primary patency of the operated segment after hybrid techniques was higher than after open and endovascular surgical interventions.

Keywords: Peripheral arterial disease, hybrid intervention, claudication

\footnotetext{
(ब) (1)

(C) The Author(s) 2018. Open Access This article is licensed under a Creative Commons Attribution 4.0 International License (https://creativecommons.org/licenses/by/4.0/), which permits unrestricted use, sharing, adaptation, distribution and reproduction in any medium or format, for any purpose, even commercially, as long as you give appropriate credit to the original author(s) and the source, provide a link to the Creative Commons license, and indicate if changes were made.
} 


\section{INTRODUCTION}

The comparative evaluation of the outcome after infrainguinal arterial disease (IAD) revascularization demonstrates controversial results ${ }^{[1]}$.

Bypass operations are the method of choice in the treatment of patients with IAD on the background of critical ischemia of the lower extremities ${ }^{[2,3]}$. However, open interventions for distal segment are not always effective; there is a great deal of blood loss and the risk of infectious complications in comparison with minimally invasive interventions (balloon angioplasty and stenting) ) $^{[4,5]}$. The latter are now becoming increasingly common ${ }^{[6]}$. Often endovascular interventions are used in the tibial artery reconstructions due to the high risk of poor wound healing after open operations ${ }^{[7]}$. But the use of endovascular technologies at the level of the femoro-tibial segment is difficult with extensive stenotic and occlusive lesions, as well as arteries with wall calcification ${ }^{[8]}$.

The ascending spread of hybrid techniques has allowed the improvement of the results of surgical interventions at both proximal and distal segments, including patients with multilevel lesions, since the combined use of open and endovascular methods of revascularization allows to summarize the positive sides of each technique and to reduce the number of possible complications due to minimal trauma ${ }^{[9]}$.

Aim: to make a comparative assessment of the use of various reconstructive methods in the atherosclerotic lesions of the femoro-tibial segment.

\section{METHODS}

Two hundred and fifty-three patients with atherosclerotic lesions of arteries below the inguinal ligament were examined. According to the type of performed reconstruction, the patients were divided into 3 groups: the first group consisted of 98 patients who underwent open operative (OO) interventions; the second group consisted of 116 people who underwent endovascular procedures (EP): balloon angioplasty of femoral, popliteal or tibial arteries; the third group consisted of 39 patients, who had undergone hybrid surgery techniques (HS).

The primary endpoint was development of thrombosis of the operated segment, bleeding and surgical site infection, the need for re-interventions and amputations within 30 days after primary revascularization.

All patients underwent carbohydrate and lipid metabolism analysis: fasting glucose level, a day glucose fluctuations; for assessing of lipid metabolism the level of total cholesterol and its fractions were analyzed, as well as the atherogenicity coefficient value. The measurement of blood pressure in the perioperative period was carried out by direct and indirect methods.

Diabetes was diagnosed in accordance with the WHO recommendations. The evaluation of hypertension was carried out according to the WHO and the International Society for Hypertension classifications. The analysis of chronic heart failure (CHF) was carried out according to the New York Heart Association classification. All patients underwent a measurement of the ankle-brachial index before and after surgery; duplex scanning, $\mathrm{CT}$ angiography to determine the features of atherosclerotic lesion of the lower extremities arteries.

The frequency of patient concomitant disease is presented in Table 1.

Variants of the performed operations are presented in Table 2.

The evaluation of the operation time duration, blood loss volume, length of stay in the intensive care unit, inhospital stay days, fluctuations in blood pressure and blood glucose level. In the postoperative period the 
Table 1. Patient characteristics and concomitant disease

\begin{tabular}{|c|c|c|c|c|}
\hline Criteria & 00 & EP & HS & $P$ \\
\hline Sex, female, $n(\%)$ & $26(26.53 \%)$ & $50(43.1 \%)$ & $12(30.77 \%)$ & 0.03 \\
\hline Age, year & $70.47 \pm 9.1$ & $65.87 \pm 10.3$ & $65.45 \pm 11.9$ & 0.001 \\
\hline Diabetes, $n(\%)$ & $37(37.76 \%)$ & $13(11.21 \%)$ & $10(25.64 \%)$ & 0.001 \\
\hline Hypertonic disease (HD), $n(\%)$ & $85(86.73 \%)$ & $101(87.07 \%)$ & $28(71.79 \%)$ & 0.06 \\
\hline 2 stage of $\mathrm{HD}, n(\%)$ & $59(60.20 \%)$ & $74(75.51 \%)$ & $23(58.97 \%)$ & 0.43 \\
\hline 3 stage of $\mathrm{HD}, n(\%)$ & $23(23.47 \%)$ & $20(17.24 \%)$ & $5(12.82 \%)$ & \\
\hline $\mathrm{CHF}^{*}, n(\%)$ & $37(37.76 \%)$ & $89(76.72 \%)$ & $17(43.59 \%)$ & 0.001 \\
\hline $\mathrm{CHF}, 2$ st by NYHA, $n(\%)$ & $23(23.47 \%)$ & $72(62.07 \%)$ & $10(25.64 \%)$ & 0.08 \\
\hline $\mathrm{CHF}, 3$ st by NYHA, $n(\%)$ & $11(11.23 \%)$ & $17(14.65 \%)$ & $7(17.95 \%)$ & \\
\hline $\mathrm{CAD}^{\star}, n(\%)$ & $81(82.65 \%)$ & $104(89.66 \%)$ & $28(71.79 \%)$ & 0.10 \\
\hline CAD, F/Class $1-2, n(\%)$ & $60(61.23 \%)$ & $61(52.59 \%)$ & $14(35.89 \%)$ & 0.075 \\
\hline CAD, F/Class 3-4, $n(\%)$ & $21(21.43 \%)$ & $43(37.07 \%)$ & $10(25.64 \%)$ & \\
\hline Myocardial infarction, $n$ (\%) & $8(8.16 \%)$ & $9(7.76 \%)$ & $12(30.77 \%)$ & 0.001 \\
\hline Chronic kidney disease, $n$ (\%) & $21(21.43 \%)$ & $23(19.83 \%)$ & $6(15.38 \%)$ & 0.72 \\
\hline Smoking, $n(\%)$ & $69(70.41 \%)$ & $58(50 \%)$ & $10(25.64 \%)$ & 0.001 \\
\hline $\mathrm{CVD}^{\star}, n(\%)$ & $27(27.55 \%)$ & $45(38.79 \%)$ & $7(17.95 \%)$ & 0.009 \\
\hline
\end{tabular}

${ }^{\star}$ CVD: cerebrovascular disease; CHF: chronic heart failure; NYHA: New York Heart Association; CAD: coronal arterial disease; OO: open operative; EP: endovascular procedures; HS: hybrid surgery techniques

\section{Table 2. Surgical interventions}

\begin{tabular}{|c|c|c|c|}
\hline Type of surgery & 00 & EP & HS \\
\hline Superficial femoral artery loop endartherectomy & 27 & - & 2 \\
\hline Femoro-popliteal bypass above knee & 17 & - & 30 \\
\hline Femoro-popliteal bypass under knee & 49 & - & 7 \\
\hline Femoro-tibial bypass & 5 & - & - \\
\hline Balloon angioplasty of the superficial femoral artery, popliteal or tibial arteries & - & 116 & 39 \\
\hline
\end{tabular}

OO: open operative; EP: endovascular procedures; HS: hybrid surgery techniques

following criteria were assessed: the primary patency of the operated segment, the incidence of complications (thrombosis of the surgical site, bleeding, infectious complications, myocardial infarction, stroke, acute renal failure), the need for re-intervention on the operated segment and the number of amputations in the first 30 days after primary intervention.

Statistical processing of the obtained results was carried out using the Stata Statistica 10 data analysis package. We used the Kolmogorov-Smirnov criterion for determining the normality of the quantitative data distribution. The quantitative characteristics were presented in the following form: mean \pm standard deviation. The identification of differences between groups was detected using the nonparametric MannWhitney $U$ test ( $t$-test). The description of qualitative features was carried out in the form of relative frequencies and expressed as a percentage. The reliability of the distribution of qualitative characteristics was determined using the $\chi^{2}$ criterion. Differences between groups are considered reliable at $P<0.05$.

\section{RESULTS}

Among the patients from the EP group, the greatest number of people with CHF and cerebrovascular disease were present. The group with hybrid operations contained the greatest proportion of people with postinfarction cardiosclerosis, that indicating a minimal invasive of this intervention. Among patients with open reconstruction were persons of the oldest age, and they were associated with a significant degree of calcification and prolonged occlusive-stenotic lesion [Table 1].

The degree of ischemia and features of atherosclerotic lesions were differentiated based on Transatlantic Intersociety Classification II (TASC II) in Figures 1 and 2. 
60

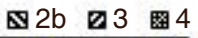

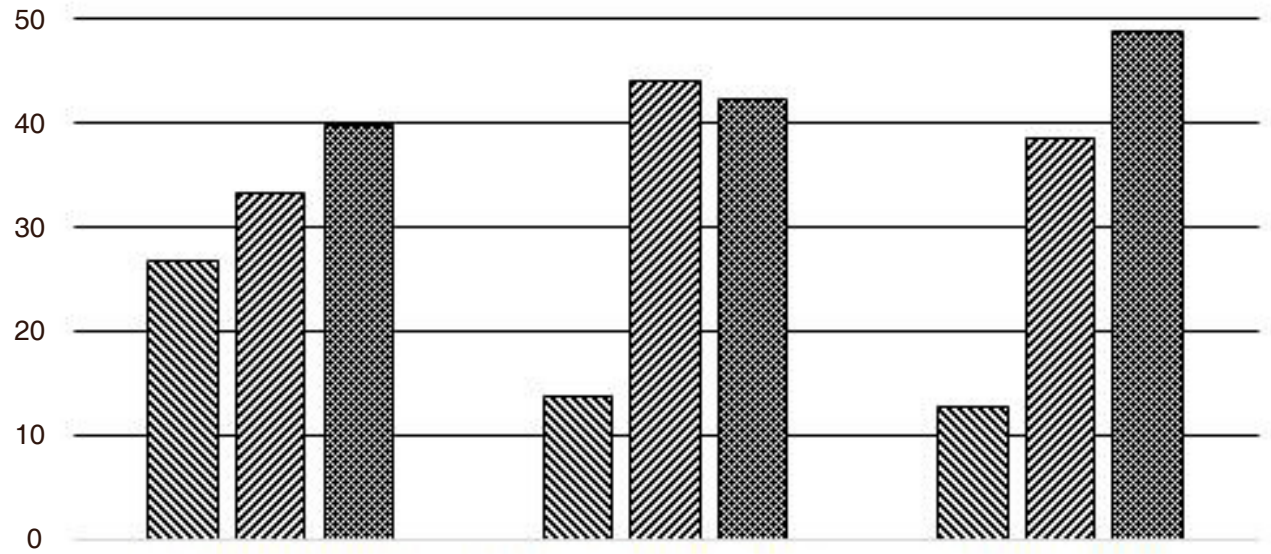

Open operations

Endovascular procedures

Hybrid surgery

Figure 1. Patient distribution with different ischemia level in clinical groups, $y$-axis - \%

\section{Fem-popliteal lesion by TASC II}

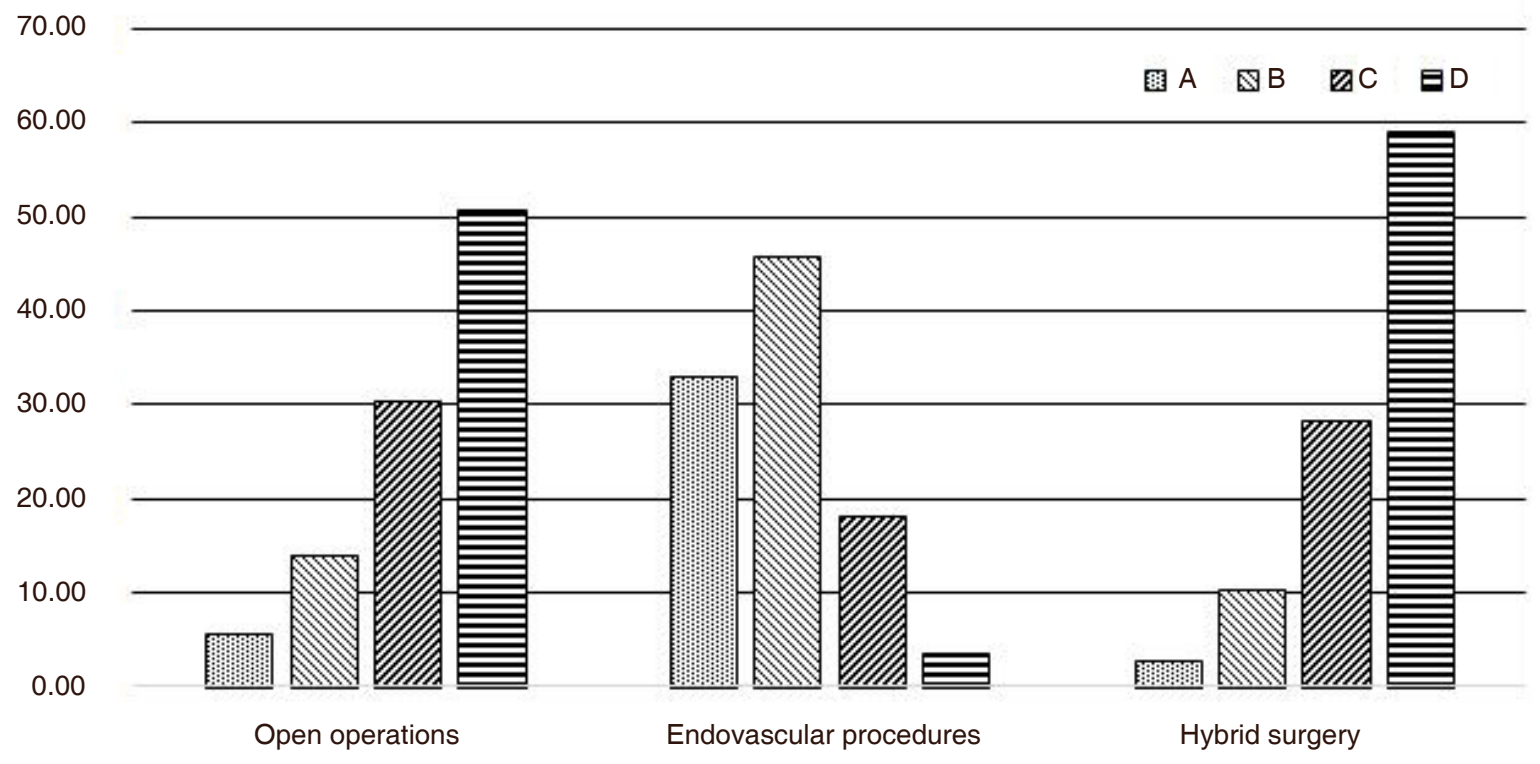

Figure 2. Distribution of atherosclerotic lesions $A / B$ and $C / D$ according to TASC II between clinical groups, $y$-axis - \%

The greatest number of patients with critical ischemia was recorded in the HS group, the lowest in the OO group, which is due to the restriction on performing open reconstructions against the background of trophic changes (according to Rutherford).

The maximum number of persons with C/D lesions by TASC II were noted in the HS group; the minimum is in the EP group.

Analyzed metabolic changes in patient groups are shown in Table 3. 
Table 3. Patients metabolic disorders in clinical groups

\begin{tabular}{|c|c|c|c|c|}
\hline Metabolic changes & 00 & EP & HS & $\boldsymbol{P}$ \\
\hline Fasting glucose level, $\mathrm{mmol} / \mathrm{L}$ & $7.13 \pm 1.9$ & $7.32 \pm 1.9$ & $6.34 \pm 2.5$ & 0.02 \\
\hline Cholesterol, mmol/L & $6.79 \pm 1.1$ & $7.73 \pm 1.6$ & $6.66 \pm 1.7$ & 0.001 \\
\hline Triglycerides, mmol/L & $1.77 \pm 0.8$ & $2.08 \pm 1.4$ & $3.33 \pm 1.4$ & 0.001 \\
\hline Low-density lipoproteins, mmol/L & $4.08 \pm 1.1$ & $4.49 \pm 1.2$ & $3.77 \pm 1.5$ & 0.02 \\
\hline High-density lipoproteins, mmol/L & $0.92 \pm 0.3$ & $1.08 \pm 0.4$ & $1.05 \pm 0.3$ & 0.06 \\
\hline Atherogenicity coefficient & $7.23 \pm 2.7$ & $6.67 \pm 2.6$ & $5.38 \pm 2.8$ & 0.01 \\
\hline Body mass index & $27.88 \pm 3.6$ & $28.48 \pm 3.6$ & $28.17 \pm 2.7$ & 0.43 \\
\hline $\mathrm{sBP}, \mathrm{mmHg}$ & $148.45 \pm 18.1$ & $153.47 \pm 20.5$ & $156.00 \pm 20.3$ & 0.03 \\
\hline $\mathrm{dBP}, \mathrm{mmHg}$ & $86.29 \pm 8.3$ & $79,64 \pm 13.2$ & $85.88 \pm 7.1$ & 0.001 \\
\hline$A B I$ & $0.40 \pm 0.1$ & $0.43 \pm 0.1$ & $0.39 \pm 0.1$ & 0.28 \\
\hline
\end{tabular}

sBP: systolic blood pressure; dBP: diastolic blood pressure; ABI: ankle-brachial index; OO: open operative; EP: endovascular procedures; HS: hybrid surgery techniques

It should be noted that significant metabolic changes were registered in all analyzed groups, including significant disturbances of carbohydrate and lipid metabolism. But with a severe lipid balance violation, the method of choice for intervention was conventional.

The blood loss during hybrid interventions was significantly less than in the case of open reconstruction operations: this circumstance is especially significant considering the comorbid characteristics of patients from the OO group.

The time of patients' stay in the intensive care unit was shortest after endovascular interventions and longest after open methods of reconstruction. Hemodynamic instability was often noted after open operations.

As a result of hybrid surgery, there was no need for re-intervention and amputations. The primary patency of the operated segment in this group in the early postoperative period was $100 \%$.

The postoperative period after open reconstructions was characterized by a relatively high incidence of complications: thrombosis of the operated segment and surgical site infection. Among patients who underwent hybrid interventions such negative outcomes were not recorded.

The number of perioperative myocardial infarctions were not different in groups of OO and EP with significant invasiveness of open surgery.

Features of the perioperative period are indicated in Table 4.

When analyzing the results of revascularization, depending on the degree of ischemia according to FonteinPokrovsky classification, the complicated course of the postoperative period prevailed in cases of critical ischemia [Table 5].

\section{DISCUSSION}

Data on the effectiveness of various revascularization techniques for lesions of the femoral-popliteal segment are ambiguous: some authors state the best primary patency of shunting surgeries and the worst results of endovascular techniques: low values of primary patency (58\%), high percentage of limb loss one year after surgery ${ }^{[10]}$. Other authors consider endovasal interventions as the method of choice in the distal type of lesion ${ }^{[11,12]}$. Data from several studies did not reveal a difference in the immediate outcomes of open and endovascular surgical interventions ${ }^{[13]}$. 
Table 4. Characteristics of the perioperative period

\begin{tabular}{|c|c|c|c|c|}
\hline Perioperative period & 00 & EP & HS & $\boldsymbol{P}$ \\
\hline Durations of the $\mathrm{OO}, \min$ & $206.17 \pm 84.73$ & - & $175.00 \pm 92.95$ & 0.19 \\
\hline Durations of the EP, min & - & $90.63 \pm 53.36$ & $77.50 \pm 66.22$ & 0.22 \\
\hline BP fluctuation during the operation, $\mathrm{mmHg}$ & $40.62 \pm 23.33$ & $30.55 \pm 14.15$ & $35.83 \pm 14.48$ & 0.001 \\
\hline Blood loss, mL & $790.93 \pm 244.32$ & - & $473.91 \pm 177.01$ & 0.001 \\
\hline ICU* staying, h & $29.76 \pm 18.79$ & $15.63 \pm 7.03$ & $25.88 \pm 9.73$ & 0.001 \\
\hline Myocardial infarction, $n(\%)$ & $2(2.04 \%)$ & $2(1.72 \%)$ & - & 0.68 \\
\hline Stroke, $n(\%)$ & $1(1.02 \%)$ & - & - & 0.45 \\
\hline Operated segment thrombosis, $n(\%)$ & $8(8.16 \%)$ & $2(1.72 \%)$ & - & 0.02 \\
\hline Bleeding, $n(\%)$ & $4(4.08 \%)$ & $3(2.59 \%)$ & - & 0.30 \\
\hline Surgical site infection, $n(\%)$ & $10(10.2 \%)$ & $4(3.45 \%)$ & - & 0.02 \\
\hline Primary patency, $n(\%)$ & $83(84.69 \%)$ & $113(88.79 \%)$ & $39(100 \%)$ & 0.01 \\
\hline Re-intervention, $n$ (\%) & $15(15.31 \%)$ & $13(11.21 \%)$ & - & 0.04 \\
\hline Amputations, $n(\%)$ & $8(8.163 \%)$ & $6(5.17 \%)$ & - & 0.16 \\
\hline
\end{tabular}

*ICU: intensive care unit; OO: open operative; EP: endovascular procedures; HS: hybrid surgery techniques; BP: blood pressure

Table 5. Features of the operating period depending on the degree of ischemia

\begin{tabular}{|c|c|c|c|c|}
\hline Operation & Degree of ischemia & 00 & EP & $\boldsymbol{P}$ \\
\hline \multirow[t]{2}{*}{ Operated segment thrombosis, $n(\%)$} & Claudication & $2(3.6 \%)$ & - & 0.04 \\
\hline & $\mathrm{CLI}$ & $6(11.6 \%)$ & $2(2.02 \%)$ & 0.006 \\
\hline \multirow[t]{2}{*}{ Bleeding, $n(\%)$} & Claudication & $1(1.8 \%)$ & - & 0.156 \\
\hline & $\mathrm{CLI}$ & $3(5.8 \%)$ & $3(3.03 \%)$ & 0.307 \\
\hline \multirow[t]{2}{*}{ Surgical site infection complication, $n$ (\%) } & Claudication & $4(8.7 \%)$ & $1(6.25 \%)$ & 0.421 \\
\hline & $\mathrm{CLI}$ & $6(14.0 \%)$ & $3(3.03 \%)$ & 0.006 \\
\hline \multirow[t]{2}{*}{ Re-intervention in 30 days, $n$ (\%) } & Claudication & $3(6.5 \%)$ & $1(6.25 \%)$ & 0.775 \\
\hline & $\mathrm{CLI}$ & $11(21.2 \%)$ & $12(12.12 \%)$ & 0.087 \\
\hline \multirow[t]{2}{*}{ Amputations, $n(\%)$} & Claudication & $1(1.8 \%)$ & - & 0.156 \\
\hline & CLI & $7(13.5 \%)$ & $6(6.06 \%)$ & 0.06 \\
\hline
\end{tabular}

CLI: critical limb ischemia; OO: open operative; EP: endovascular procedures

The advantages of endovasal techniques include minimal invasiveness and, accordingly, good tolerability of the operation, which is especially important for patients with combined lesions of the lower extremity arteries and arteries of the coronary or carotid pool ${ }^{[14]}$. Among the shortcomings of EP, there is the risk of restenosis and thrombosis at the level of the operated segment, as well as limitations due to anatomical features ${ }^{[15]}$. According to the results of this study, endovascular techniques are characterized by a lower primary patency compared to open and hybrid interventions within 30 days after the intervention.

The main disadvantages of open methods are: a significant probability of infectious complications, a longer surgical time and a significant surgical risk $^{[13]}$. In this study, a significant frequency of so-called "large" complications in the group of open operations was noted in the early period after the intervention.

Hybrid surgical interventions were characterized by positive outcomes at an early stage, combining the advantages of open and endovascular techniques ${ }^{[16]}$. As a result, hybrid operations are characterized by a lower incidence of limb loss ${ }^{[17]}$. According to the present study there were no amputations recorded in the early period after hybrid interventions.

Advantages of hybrid techniques in comparison with open reconstructions are reduced duration of hospitalization and blood $\operatorname{loss}^{[18]}$. It is also interesting to note that the difference between hybrid and endovascular reconstructions was in the smaller amount of contrast used and the lesser occurrence of bleeding in the puncture zone ${ }^{[19]}$. All this contributes to reducing the risk of contrast-induced nephropathy, as well as other complications, reducing the cost of hybrid surgical interventions compared with open 
methods due to shorter hospitalization times and insignificant time spent in the intensive care unit ${ }^{[2]}$. According to the present study, the length of hospitalization and the amount of blood loss were less in HS than in the group of open operations.

Quantitative differences between the analyzed groups should be considered as the limitation of this study, as well as the lack of information on the long-term results.

Conclusion: hybrid technologies are characterized by a shorter duration of surgical intervention, a low amount of blood loss and a lower incidence of complications in the early periods. These findings open new prospects for revascularization in persons with severe comorbid pathology.

\section{DECLARATIONS}

\section{Authors' contributions}

Data collection, data analysis, manuscript writing: Michael I, Petr P

Statistical analysis, manuscript review: Michael I, Anastasia A, Pavel B

Manuscript editing and reviewing: Petr $\mathrm{P}$

Study supervisor, manuscript reviewing: Nikolay G

Data collection: Tigrov I, Anastasia U

\section{Availability of data and materials}

At request. Kindly email corresponding author.

\section{Financial support and sponsorship}

None.

\section{Conflicts of interest}

All authors declared that there are no conflicts of interest.

\section{Ethical approval and consent to participate}

This report is not considered research by NHS, as defined by the UK Policy Framework for Health and Social Care Research. An informed consent of participation in the study was obtained from participants and approved from NHS Research Ethics Committee (REC). There was no children under 16 participate in this study.

\section{Consent for publication}

Not applicable.

\section{Copyright}

(c) The Author(s) 2018.

\section{REFERENCES}

1. Krotovsky GS, Zudin AM. Tactics of treatment of patients with critical ischemia of the lower extremities. Available from: http:// textarchive.ru/c-1061963.html. [Last accessed on 26 Oct 2018] (in Russian)

2. Nicoloff AD, Taylor LM Jr, McLafferty RB, Moneta GL, Porter JM. Patient recovery after infrainguinal bypass grafting for limb salvage. J Vasc Surg 1998;27:256-63.

3. Rutherford RB, Baker JD, Ernst C, Johnston KW, Porter JM, et al. Recommended standards for reports dealing with lower extremity ischemia: revised version. J Vasc Surg 1997;26:517-38.

4. Dosluoglu HH, Lall P, Cherr GS, Harris LM, Dryjski ML. Role of simple and complex hybrid revascularization procedures for symptomatic lower extremity occlusive disease. J Vasc Surg 2010;51:1425-35. 
5. Glushkov NI, Ivanov MA, Artemova AS, Petrov DA, Maksimkina ES. The infection in vascular surgery and metabolic syndrome: a coincidence or correlation? Kardiologiya I Serdechno-Sosudistaya Khirurgiya 2017;10:56-61. (in Russian)

6. Russian Society of Surgeons. National recommendations for the management of patients with diseases of arteries of lower extremities. Available from: http://xn----9sbdbejx7bdduahou3a5d.xn--p1ai/upload/disease_arteries.pdf. [Last accessed on 26 Oct 2018] (in Russian)

7. Matsagkas M, Kouvelos G, Arnaoutoglou E, Papa N, Labropoulos N, et al. Hybrid procedures for patients with critical limb ischemia and severe common femoral artery atherosclerosis. Ann Vasc Surg 2011;25:1063-9.

8. Uchkin IG, Shugushev ZKh, Talov NA, Bagdasaryan AG, Gonsales AK, et al. Experience with hybrid techniques of surgical treatment of patients with lower limb critical ischaemia. Angiol Sosud Khir 2013;19:48-57. (in Russian)

9. Koidan AA, Batalin IV, Vavilov VN, Kaputin Y, Atmadzas AV, et al. Comparative results of various methods of arterial reconstruction in the defeat of the femoral-popliteal segment in patients with chronic critical ischemia of the lower limbs. Reg Blood Circ Microcir 2017;16:41-8. (in Russian)

10. Gordon IL, Conroy RM, Arefi M, Tobis JM, Stemmer EA, et al. Three-year outcome of endovascular treatment of superficial femoral artery occlusion. Arch Surg 2001;136:221-8.

11. Clark TW, Groffsky JL, Soulen MC. Predictors of long-term patency after femoropopliteal angioplasty: results form the STAR registry. J Vasc Interv Radiol 2001;12:923-33.

12. Cvetanovski MV, Jovev S, Cvetanovska M, Blazevski B, Colanceski R, et al. Femoropopliteal bypass vs percutaneous transluminal angioplasty and stenting in treatment of peripheral artery diseases of infrainquinal segment - short-term results. Priloz 2009;30:105-18.

13. Glushkov NI, Ivanov MA, Artemova AS. Results of various revascularization methods in patients with critical ischemia of the lower limbs in the background of peripheral atherosclerosis. Kardiologiya I Serdechno-Sosudistaya Khirurgiya 2017;10:50-6. (in Russian)

14. Zatevakhin I, Shipovsky V, Zolkin V. Balloon angioplasty in ischemia of lower limbs. Moscow: Medicine Pub; 2004. (in Russian)

15. Eroshkin IA, Eroshenko AV, Vasilev UG, Kokov LS. Results of endovascular methods for the treatment of critical ischemia of the lower limbs in patients with diabetes mellitus. Int J Interv Cardioangiol 2008;14:36-36a. (in Russian)

16. Antoniou GA, Sfyroeras GS, Karathanos C, Achouhan H, Koutsias S, et al. Hybrid endovascular and open treatment of severe multilevel lower extremity arterial disease. Eur J Vasc Endovasc Surg 2009;38:616-22.

17. Schillinger M, Diehm N, Baumgartner I, Minar E. TASC II section F on revascularization: commentary from an intervencionist's point of view. J Endovasc Ther 2007;14:734-42.

18. Troitskii AV, Bekhtev AG, Khabazov RI, Beliakov GA, Lysenko ER, et al. Outcomes of hybrid operations in multi storeyed lesions of arteries of the aortoiliac and femoropopliteal segments. Angiol Sosud Khir 2012;6:67-77. (in Russian)

19. Nishibe T, Kondo Y, Dardik A, Muto A, Koizumi J, et al. Hybrid surgical and endovascular therapy in multifocal peripheral TASC D lesions: up to three-year follow-up. J Cardiovasc Surg (Torino) 2009;50:493-9.

20. Thomas M. Ttreatment of chronic lower limb ischemia. In: Jonathan DB, editor. Vascular and endovascular surgery. USA: Elsevier; 2006. pp. 35-6. 